\title{
PSICANÁLISE E BIOPOLÍTICA: O FASCÍNIO DO DISCURSO MÉDICO
}

\author{
Psychoanalysis and Biopolitics: The Fascination of Medical Discourse
}

Psicoanálisis y Biopolítica: El Encanto del Discurso Médico

\section{Psychanalyse et Biopolitique: La Fascination du Discours Médical}

DOI: $10.5020 / 23590777 . r s . v 18 i E s p .6591$

\section{Leonardo Danziato (Lattes)}

Professor Doutro do Programa de Pós-Graduação em Psicologia da Unifor; Psicanalista Analista Membro da Invenção Freudiana.

\section{Ana Carolina B. L. Martins (Lattes)}

Psicóloga, psicanalista, doutora em teoria psicanalítica UFRJ, professora do curso de psicologia da Faculdade Maurício de Nassau.

\section{Sabrina Serra Matos (Lattes)}

Psicóloga, psicanalista, mestre em Saúde Pública UFC, professora da Universidade de Fortaleza - UNIFOR.

\section{Resumo}

Este trabalho visa interrogar as causas e os processos discursivos relacionados ao fascínio que o modelo hegemônico da medicina descritiva exerce sobre os profissionais e os alunos dos cursos de psicologia, e também sobre a população como um todo. Buscamos politizar a questão, partindo da discussão mais ampla sobre os manuais classificatórios DSM e CID e suas consequências para o crescente movimento de "autodiagnose". Em seguida, em uma análise epistemológica, investigamos a histórica e problemática constituição da psiquiatria no campo médico, bem como as possíveis razões para a adesão ao discurso psiquiátrico por parte do campo psicológico. Tal trajeto nos permitiu introduzir uma análise genealógica e crítica da legitimação do saber médico em nossa cultura, realizada a partir do conceito foucaultiano de biopolítica. Nas conclusões, trabalhando com a teoria lacaniana dos quatro discursos, pudemos apontar o quanto a conjunção entre ciência e capitalismo, constatada na dominância do discurso médico, inviabiliza um lugar para o sujeito e para o seu não saber.

Palavras-chave: psicanálise; biopolítica; discurso médico.

\section{Abstract}

This work aims to interrogate the causes and discursive processes related to the fascination that the hegemonic model of descriptive medicine plays on the professionals and students of psychology courses, as well as on the population as a whole. We sought to politicize the issue from the broader discussion of the DSM and ICD classificatory manuals and their consequences for the growing "self-diagnosis" movement. Then, in an epistemological analysis, we investigate the historical and problematic constitution of psychiatry in the medical field, as well as the possible reasons for adherence to the psychiatric discourse by the psychological field. This path allowed us to introduce a genealogical and critical analysis of the legitimation of medical knowledge in our culture, based on the Foucaultian concept of biopolitics. In the conclusion, working with the Lacanian theory of the four discourses, we could point out how much the conjunction between science and capitalism, verified in the dominance of medical discourse, makes a place for the subject and his non-knowledge impossible.

Keywords: psychoanalysis; biopolitics; medical discourse. 


\section{Resumen}

Este trabajo objetiva interrogar las causas y los procesos discursivos relacionados al encanto que el modelo hegemónico de la medicina descriptiva ejerce sobre los profesionales y los alumnos de los cursos de psicología y también sobre la populación como un todo. Buscamos politizar la cuestión, partiendo de la discusión más amplia sobre los manuales clasificatorios DSM y CID y sus consecuencias para el creciente movimiento de "auto-diagnostico". Después, en un análisis epistemológico, investigamos la histórica y problemática constitución de la psiquiatría en el campo médico, así como las posibles razones para la adhesión al discurso psiquiátrico por parte del campo psicológico. Tal trayecto nos permitió introducir un análisis genealógico y crítico de la legitimación del saber médico en nuestra cultura, realizada a partir del concepto foucautiano de biopolitica. En las conclusiones, trabajando con la teoría lacaniana de los cuatro discursos, hemos podido apuntar lo cuanto la conjunción entre ciencia y capitalismo, constatada en el dominio del discurso médico inviabiliza un lugar para el sujeto y para su no saber.

Palabras clave: psicoanálisis; biopolítica; discurso médico.

\section{Résumé}

Ce travail vise à questionner les causes et les processus discursifs liés à la fascination que le modèle hégémonique descriptif a sur les professionnels et les étudiants de psychologie, bien comme sur la population dans son ensemble. On essaye de politiser cette question en commençant par le plus large débat sur les manuels de classification DSM et ICD et leurs conséquences dans le mouvement d '«auto-diagnostic». Puis, dans une analyse épistémologique, on étudie la constitution historique et problématique de la psychiatrie dans le domaine médical, ainsi que les possibles raisons de l'adhésion de la psychologie au discours psychiatrique. Ce chemin nous permet d'introduire une analyse généalogique et critique de la légitimation du savoir médical dans notre culture, basée sur le concept foucaldien de biopolitique. Pour conclure, le travail avec la théorie lacanienne des quatre discours rendre possible de montrer comment la conjonction entre la science et le capitalisme, laquelle est constatée dans la prédominance du discours médical, permet la création d'un place pour le sujet et son non-savoir.

Mots-clés: psychanalyse; biopolitique; discours médical.

Em nossa prática docente num curso de psicologia, mas também na mídia de forma geral, assim como nas práticas discursivas no laço social, deparamo-nos com todo um processo de psiquiatrização da vida, de medicalização das subjetividades e dos sujeitos, cujo sinal mais evidente é a utilização do reducionismo classificatório dos manuais de diagnóstico psiquiátrico - os DSM's e CID’s. Nas clínicas-escolas dos cursos de graduação em psicologia, por exemplo, vivemos o paradoxo vexatório de ter que adequar nossas práticas a uma classificação DSM, exigida pelo SUS, que não provém dos quadros teórico-clínicos da psicologia.

Essa situação suscita várias questões: afinal, para que servem as teorias psicopatológicas em psicologia, se não para referenciar suas práticas clínicas? Qual a função de uma classificação desta ordem, na direção de uma prática clínica psicológica? A lógica a-teórica e puramente descritiva dos DSM's, coaduna com o rebuscamento psíquico estudado no campo da psicologia? Existe algum ganho prático na utilização desses diagnósticos no campo da saúde mental? O que faz com que nos submetamos a esse reducionismo ingênuo, ideológico e segregatório das classificações psiquiátricas? Certamente, não se trata de uma aplicação da teoria na prática, já que essas nosografias, como dissemos, não provêm dos estudos e pesquisas em psicologia, ou em psicanálise. Isso nos leva a entender que se trata de uma submissão política, e não epistemológica. É curioso constatar que várias escolas de psicologia - especialmente as que se consideram as mais científicas - não se oponham a essa lógica, e façam uso indiscriminado dessas classificações.

Este trabalho busca interrogar as causas e os processos discursivos por trás da submissão e fascínio que esse modelo hegemônico do discurso médico produz em profissionais e estudantes de psicologia, mas também na população como um todo, que aceitou passivamente todo um movimento de medicalização da vida, dos corpos e das subjetividades. Como opera esse fascínio? Por que será que esses quadros classificatórios encantam aqueles que, em tese, deveriam estar advertidos contra um dispositivo tão flácido em termos conceituais, epistemológicos e metodológicos, como os profissionais e estudantes de psicologia? Por que esse movimento de "servidão voluntária" nas práticas profissionais e de ensino em psicologia?

Estabeleceremos uma discussão que perpassa, inicialmente, uma constatação desse fascínio e a utilização dos discursos médicos e das classificações psiquiátricas no campo da psicologia, para que possamos, em seguida, tentar destrinchar os 
mecanismos discursivos e políticos por trás desse fenômeno, lançando mão de uma leitura crítica arqueo-genealógica mas também de uma oposição oriunda da consideração da singularidade da função sujeito por parte do campo psicanalítico.

\section{Os Manuais de Classificação: Um Universal sem Singular}

Atualmente, são dois os manuais que propõem essas classificações diagnósticas: o DSM-5: Manual diagnóstico e estatístico de transtornos mentais (2014), publicado pela Associação Psiquiátrica Americana, e o CID-10: Classificação Estatística Internacional de Doenças (1994), publicada pela OMS. Enquanto manuais, eles funcionam no sentido de encaixar os sujeitos numa descrição "universal" dos seus sintomas e, assim, diagnosticá-los e classificá-los. Ambos são nosografias, ou seja, descrevem quadros a partir de sintomas. Não são uma nosologia, que seria um estudo dos quadros patológicos, já que simplesmente apresentam os sintomas que devem estar presentes para que o profissional sustente um diagnóstico.

Fica claro que não há espaço, não há brecha alguma para que, por esses dispositivos, possamos pensar no sujeito - função tão cara para a psicanálise. Nesses dispositivos classificatórios, há uma homogeneização das subjetividades, pois todos são pensados como idênticos na medida em que apresentam sintomas semelhantes. Nesses manuais a-teóricos é possível seguirmos essa linha de raciocínio mencionada por Jurandir Freire (1994, p.132) em um de seus artigos: "não sabemos o que é o sofrer porque conhecemos a físico-química da serotonina; temos interesse no conhecimento da serotonina porque sabemos o que é o sofrer". Pode ser que a tal serotonina seja uma explicação, mas não diz absolutamente nada sobre um sujeito e sua história.

Por conta da instalação no laço social dessa lógica discursiva, atualmente, qualquer pessoa pode obter um diagnóstico como portador de um determinado transtorno. Na verdade, há todo um curioso movimento de autodiagnóstico por parte da população, já que obtém nos sites da internet algumas instruções e recomendações sobre como se autodiagnosticar (Souza, 2013). Essa servidão e aceitação desses diagnósticos, mais do que comprovar o sucesso e o rigor de tais práticas, indicam a forma como elas respondem a uma demanda social de um saber nominativo, de um nome para definir e ancorar a angústia e o mal-estar comuns da vida. Além do que, qualquer relato por parte do sujeito serve como motivo para se adequar um diagnóstico. Vivemos uma febre diagnóstica sem precedentes.

Outra característica importante dos manuais psiquiátricos é que eles dissolveram uma lógica estrutural própria da "psiquiatria dinâmica", que a acompanhava essa clínica desde o século XIX (Henriques, 2003), em nome de uma categoria indefinida e pouco rigorosa como o "transtorno mental". Categorias, como neuroses e psicoses, foram transmutadas para "transtornos psicóticos", ou outras infindáveis nomeações meramente descritivas.

A lógica estrutural se esvaiu, o que indica uma predominância de um pragmatismo como pano de fundo epistemológico e ideológico, que figura como um dos pressupostos teóricos da medicalização (Calazans \& Lustoza, 2008). Nessa perspectiva, a verdade passa a ser entendida como o que ancora suas consequências de utilidade no sentido de promover o bem-estar da humanidade (Rorty, 1998). Como afirmam Calazans e Lustoza (2008),

... ao ser transformado em fundamento filosófico da clínica psi, o pragmatismo acaba respaldando uma prática cuja preocupação maior seria a restituição do bem-estar ao paciente, sendo considerado bem-sucedido o tratamento que consegue diminuir o sofrimento subjetivo a um baixo preço e em um tempo curto. A busca de eficácia como uma forma de reduzir custos se torna, então, o norte das políticas de saúde pública (Calazans \& Lustoza, 2008, p. 126).

O caráter ideológico do pragmatismo se espelha em seu funcionamento adaptativista, que comunga com uma lógica do mercado e subtrai as possibilidades de interrogação de um funcionamento estrutural, seja da sociedade, seja da família, seja do sujeito.

Aplicando essa lógica à clínica, adequamos a prática às exigências puramente sintomáticas, ou semiológicas, desconhecendo e desconsiderando os mecanismos envolvidos na formação dos sintomas, ou seja, dissolvendo sua lógica estrutural. Como conclui Infante (2011), trata-se de uma clínica pobre na prática e na teoria, na qual a causalidade psíquica nem sequer é mencionada.

Não é por acaso que a psicanálise dirige críticas severas a esse modus operandi classificatório (Gutfreind, 2016), já que mantém uma lógica estrutural, assim como a consideração de uma singularidade do sujeito, dirigindo o tratamento por uma ética, mais do que uma política, levando em conta a função defensiva e inconsciente dos sintomas, ou mesmo das formações elementares nas psicoses.

Eis um espaço onde podemos articular a clínica com a política através dos instrumentos lacanianos dos quatro discursos (Lacan, 1969-70/1992), mas que deixaremos para um momento posterior. 


\section{A Adesão do Campo Psicológico ao Discurso Médico}

Que o senso comum incorpore o jargão dos transtornos mentais nesse processo de autodiagnóstico da vida trata-se de um fenômeno curioso, mas nada surpreendente. A adesão ao diagnóstico responde ao mal-estar estrutural da falta de um significante eletivo, de um nome que inscreva o sujeito no laço social. Afinal, para quê sustentar a pergunta - quem sou eu? - quando há uma oferta incessante de respostas, legitimadas pelo discurso médico? Sou depressivo, sou bipolar, sou hiperativo... esses são alguns dos significantes que se 'colam' imaginariamente ao sujeito, aplacando a angústia do 'não saber', em primeira instância, sobre aquilo que se é, em segunda, sobre o que se deseja. Em tempos cujo grande Outro (A) não existe, estabelecendo a falta de significantes-mestres que dirijam o sujeito, "nomeações pequenas" - ou como diz Miller (2010), "pequenos comitês de ética" -, são estabelecidos como forma de nomear e normatizar o que antes era dado como certo pela lógica simbólico-cultural do grande Outro.

Portanto, assistimos hoje a um fenômeno ainda mais instigante e surpreendente, relacionado à multiplicação dos transtornos no âmbito da cultura: trata-se do hábito, interno ao campo psicológico, de "importar" construções teóricas e metodológicas da medicina, sem qualquer tipo de estranhamento. Tal miscelânea epistêmica não deixará de ter ressonância no futuro, nas práticas terapêuticas exercidas pelos psicólogos depois de formados.

O exemplo mais paradigmático dessa confusão de línguas epistemológicas se refere à adesão (para não dizer 'fascínio') de estudantes e professores dos cursos de psicologia por teorias, técnicas e performances provenientes do campo médico. Citemos algumas delas: o uso do jaleco em estágios clínicos, a aplicação de anamneses e exames mentais na área da saúde, a hierarquia entre psicólogos e pacientes com o intuito de simular o ato médico, a incorporação dos jargões próprios à psiquiatria, e assim por diante. Todos esses fenômenos, facilmente observáveis, convergem para dois pontos estruturalmente vinculados ao trânsito entre psicologia e medicina: o diagnóstico e o método.

O diagnóstico dos transtornos mentais e a aplicação dos métodos quantitativos, hoje, tornaram-se atividades tão comuns entre médicos e psicólogos que temos dificuldade para distinguir os estudos de caso e as discussões teóricas realizadas por uns e por outros, tamanha são as semelhanças. Para dar um exemplo, certa revista de psicomotricidade clínica publicou dois artigos com os seguintes títulos: "TDAH/I: Implicações no desenvolvimento infantil" (Genes, 2002) e "A ação terapêutica da psicomotricidade na criança com TDAH" (Thompson, 2002). Ambos descrevem o transtorno de déficit de atenção e hiperatividade em acordo com o manual psiquiátrico DSM-4: Diagnostic and Statistical Manual of Mental Disorder (2004), assim como ambos recorrem à causalidade orgânica na teorização do fenômeno, e, por fim, os dois propõem um plano terapêutico composto de avaliação médica e psicológica. Além disso, os argumentos de "frequência" e de "periodicidade" na construção do diagnóstico atravessam os dois artigos, apontando-nos para a relevância dos estudos quantitativos. A única diferença, portanto, é que um dos trabalhos fora escrito por um neuropediatra, com formação médica, e o outro por uma psicomotricista e psicopedagoga, com formação em psicologia e em educação. Diante disso, cabe a pergunta: o que seria o diagnóstico e o método próprios ao campo psicológico?

Essa questão nos direciona para as fragilidades referentes à constituição do espaço psicológico, principalmente no que diz respeito à delimitação do objeto de investigação da psicologia. Sobre esse assunto, Figueiredo (2012) nos assinala para a posição ambígua que a categoria de "sujeito" assumiu na condição do objeto dos saberes psi: ou bem o sujeito é compreendido como uma ficção a ser denunciada pela objetividade científica ou, então, ele se apresenta em toda a sua singularidade, mostrando-se refratário às leis da ciência. No primeiro caso, se o sujeito é uma ficção, caberá à ciência psicológica revelar as bases ideológicas dessa ficção, para, por fim, deixá-lo de lado. Desse modo, as matrizes psicológicas de cunho cientificista direcionaram seus esforços à construção de um novo objeto, passível de ser quantificado, controlado e previsto. No segundo, para o sujeito singular, irracional, plenamente imerso na idiossincrasia de sua própria experiência, não há teoria possível: o conhecimento científico não pode se constituir e se transmitir sobre as bases do imprevisível, e o que não tem regularidade, nem no espaço, nem no tempo, não será submetido à investigação científica. "Observa-se também, aqui, uma cisão do indivíduo. De um lado o indivíduo para si, irredutível; de outro, o indivíduo para o outro, um suporte de papéis sociais prédefinidos. Um objeto de uma psicologia que não é ciência; outro, objeto de uma ciência que não é psicologia" ( p. 22).

Diante da fragilidade do seu campo, o psicólogo fará um apelo à cientificidade médica, e resta nos perguntarmos se as expectativas aí depositadas cumprirão com seus objetivos. Afinal, a medicina que se vende nos cursos de psicologia - no caso, a psiquiatria - estaria ela em melhores condições de cientificidade quanto à constituição do seu objeto de estudo? E qual seria o objeto (e o objetivo) dessa "ciência psiquiátrica"?

\section{A Fragilidade Epistemológica da Ciência Psiquiátrica}

A leitura de Foucault (1987) e de Canguilhem (1990) muito nos ensina sobre a histórica produção do discurso médico enquanto saber positivo, legitimado pelo moderno ideal de ciência, empreitada cujas condições de possibilidade se articulam 
aos reviramentos epistêmicos do conceito de doença.

Se a doença é concebida em uma perspectiva dinâmica, de harmonia e de desarmonia em relação ao "todo", a medicina só poderá se restringir a uma prática moral: ela visará o reestabelecimento do "equilíbrio", apaziguando a eterna luta entre o normal e o patológico, entre o bem e o mal. A concepção dinâmica da doença atravessava a prática dos médicos gregos, para quem o homem se encontrava moralmente implicado, não apenas no seu adoecimento, mas também nos esforços para permanecer são. Cabe lembrar que essa concepção dinâmica não era privilégio dos gregos, atravessando a história da medicina e das práticas médicas moralizantes.

No entanto, a partir do século XVIII, o que se verifica é uma descontinuidade na concepção dinâmica: para se legitimar enquanto uma prática positiva, com resultados precisos e previsíveis, a medicina moderna deverá refutar qualquer perspectiva holística. Nesse contexto, a doença não mais fará parte do "todo" do ser humano, ela se tornará progressivamente uma entidade autônoma, assumindo uma perspectiva ontológica. O moderno projeto médico excluirá o sujeito da experiência de adoecimento: os homens não mais são a doença, como o era no caso grego. Após a microbiologia de Pasteur, no séxulo XIX, a doença passa a ser entendida enquanto um corpo estranho e indesejado, e, acima de tudo, desconhecido. Ao operar uma cisão entre a doença e o doente, o discurso médico também subtraiu do sujeito o saber sobre o patológico, relançando-o à autoridade da instituição médica (da qual o médico é apenas um 'representante', como bem nos lembra Clavreul (1983).

A consistência ontológica da doença, enquanto objeto positivo da ciência médica, só será possível com o advento do método anátomo-clínico, o qual estabelecerá uma relação causal entre o sintoma e a sua lesão orgânica correspondente: "para agir, é preciso ao menos localizar" (Canguilhem, 1990, p. 19). O advento da ciência médica se articulará intimamente à discussão sobre a etiologia orgânica das doenças, que servirá de fundamento não apenas para o diagnóstico, como também para o prognóstico e para a escolha da técnica terapêutica. Assim, a vertente pragmática do discurso médico se mostrará solidária à localização orgânica da doença.

E o que dizer de uma medicina cujo objeto, a doença, não se encontra inscrito no corpo? Como se justifica a pragmática dos tratamentos psiquiátricos?

Mesmo dentro de um contexto positivista, a medicina sempre teve de se haver com os adoecimentos de causas desconhecidas, com as mortes súbitas e as mais variadas ordens de padecimentos inexplicáveis. E aquilo que escapa à inteligibilidade médica, à consistência ontológica da doença, à certeza palpável da localização anatômica, será relegado ao metafísico e obscuro campo do 'mental': "No primeiro caso, estaríamos diante de uma doença puramente somática a exigir um tratamento sério e científico; no outro, diante de uma 'somatização'(...) é como disseram: para uma doença imaginária, uma medicina de mentirinha” (Figueiredo, 2008, p. 96-97).

Esse pequeno apanhado histórico nos serve para lembrar que a posição da psiquiatria no contexto mais amplo das ciências médicas nunca foi confortável: ou a doença mental, objeto psiquiátrico por excelência, encontrava seu respaldo em uma sede orgânica - caso em que o tíquete de ingresso ao reino médico permanecia garantido - , ou o âmbito do mental se positivava enquanto objeto independente, com leis próprias de funcionamento e, nesse caso, saía-se do campo médico em direção ao campo psicológico.

No primeiro caso, a nosologia psiquiátrica estaria respaldada pela investigação da fisiopatologia, integrando-se aos mesmos princípios positivos das demais especialidades médicas. Este seria o sonho da psiquiatria do nosso tempo: fazer da doença mental uma entidade autossuficiente, organicamente localizada e destacada da experiência subjetiva. Caberá, ao psiquiatra, a descrição objetiva dessas entidades mórbidas, articulando-as a marcadores biológicos. No segundo caso, a psiquiatria reconheceria a sua dívida com a tradição psicopatológica que sempre lhe serviu de fundamento, contando com uma pluralidade de teorias sobre a causalidade psíquica da loucura. Esta se afastaria, entretanto, do ideal de ciência, arriscando o seu pertencimento ao campo médico, mas manteria a ênfase na singularidade da experiência, base da observação clínica. Assim, "a abordagem fundamental para se credenciar a psiquiatria como especialidade médica de pleno direito seria a nosologia e não a psicopatologia" (Pereira, 2014, p. 1039).

Retornemos, então, à pergunta inicial: será que a psiquiatria, tão problematicamente situada no âmbito da cientificidade médica, será capaz de conferir legitimidade científica ao frágil e disperso campo psicológico?

A questão se torna ainda mais controversa considerando-se a paixão pelos transtornos, que tanto acomete os estudantes dos cursos de psicologia. $\mathrm{O}$ fato é que o conceito de transtorno posiciona muito mal a dimensão da causalidade, da etiologia das doenças mentais, tão cara às teorias psicopatológicas. Sob a lógica dos transtornos, a psiquiatria descritiva, base dos manuais diagnósticos, excluirá a discussão psicopatológica, descrevendo os sintomas sem se importar com a etiologia das doenças, mas também sem justificar seus fundamentos fisiopatológicos:

Cada um dos transtornos mentais é conceitualizado como uma síndrome ou padrão comportamental ou psicológico clinicamente importante. (...) Qualquer que seja a causa original, a síndrome deve ser considerada no momento como uma manifestação de uma disfunção comportamental, psicológica ou biológica do indivíduo (DSM-4, 2004, p. XXI). 
Vale lembrar que a fachada de cientificidade dos manuais diagnósticos é menos tributária do recurso à causalidade orgânica - "qualquer que seja a causa original" - do que da adesão cega a estudos estatísticos e epidemiológicos. Nesse inusitado método de pesquisa, colaboradores se encarregam de aplicar questionários em uma amostra significativa da população, para, em seguida, produzir-se um levantamento estatístico dos principais transtornos daquela amostra. Além disso, os questionários se baseiam nos dados clínicos dos próprios psiquiatras, dos principais sintomas e sinais verificados em suas clínicas, cujo crivo será a última versão dos manuais classificatórios. Também entram nesses estudos estatísticos a descrição dos efeitos dos psicofármacos e a descoberta de novas 'drogas', cujos efeitos ainda serão testados. Feito os estudos epidemiológicos e estatísticos, a inclusão ou exclusão de novas categorias diagnósticas dependerá do consenso dos psiquiatras, em votação nas reuniões da APA. Trata-se, portanto, de um círculo vicioso, em que, nessa lógica, os transtornos são produzidos "tautologiacamente".

Zarzanelli, Delgalarrondo e Benzato (2014) nos indicam uma interessante inversão metodológica, amplamente denunciada pelos próprios psiquiatras, após a publicação da quinta versão do DSM: "as investigações empíricas quase sempre partem dos recortes e distinções categoriais do DSM" (p. 330). Isso significa que, em um primeiro tempo, temos a classificação dos sintomas feita pelos manuais diagnósticos (frutos de estudos epidemiológicos), para apenas em um segundo momento serem investigadas as bases neuroquímicas e fisiológicas daquilo que já está dado enquanto fato empírico. A neurociência, a genética e a ciência cognitiva constituiriam o santo graal dos manuais classificatórios, os quais nutrem a esperança de verem suas categorias um dia confirmadas pelo avanço biomédico. "Nessa perspectiva, o erro de origem seria a atribuição, inadvertente e implícita, de 'significado biológico' a conjuntos de sintomas” (p. 330).

Assim, quando os psicólogos recorrem ao diagnóstico psiquiátrico e ao 'método estatístico' para validar suas práticas, na verdade, eles estão introduzindo, no campo psicológico, dois grandes problemas: a aversão aos estudos psicopatológicos e a deslegitimação da experiência clínica. E o que seria uma psicologia desinteressada da etiologia psíquica, que desvalorizasse a dimensão clínica em prol do organicismo?

Abordar esse reducionismo organicista é adentrar na nebulosidade do campo psiquiátrico atual. Campo esse que, na medida em que se aproxima cada vez mais das neurociências (daí as expressões neuropsiquiatria ou biopsiquiatria), mais vai perdendo os seus compromissos com a subjetividade e a clínica.

\section{A Dominância Discursiva da Biopolítica}

A partir daí, podemos afirmar que certamente a dominância discursiva da psiquiatria no mundo contemporâneo não é o efeito da eficácia nem da cientificidade "comprovada" de sua prática, já que as curas não se estabeleceram. Pelo contrário, nunca tivemos tantos adoecimentos psíquicos, observados nas pandemias de depressão e toxicomanias, tal como informadas pela OMS. Parece até que todo esse processo de medicalização agravou os adoecimentos que deveria sanar: eis o "paradoxo da droga". Mas então, como explicar a preponderância discursiva de uma prática que se fundamenta em cânones científicos tão questionáveis e o porquê de praticamente não ser interrogada de forma direta nos espaços que deveriam fazê-lo?

Para estabelecer uma resposta e uma posição sobre o debate, precisamos politizá-lo. Dois autores podem nos ajudar na composição de uma analítica que nos satisfaça e que considere o caráter político, genealógico discursivo, da questão: Foucault e Lacan.

Aprendemos com Foucault que a dominância de um discurso não depende propriamente de sua cientificidade, mas de condições de possibilidades arqueo-genealógicas, fundamentalmente políticas, que estabelecem uma "economia política dos discursos" (Foucault, 1999a). Nossa analítica, portanto, deve ser político-genealógica, e não epistemológica. Assim, é necessário saber como um determinado saber galgou a condição de poder enunciar a verdade sobre aquele tema. Como sabemos na "História da Loucura na Idade Clássica", Foucault (1991) descreveu brilhantemente todo o processo arqueológico no qual a psiquiatria, nutrida de determinadas condições de possibilidade históricas, econômicas, políticas, filosóficas, discursivas, enfim, mas não necessariamente científicas, logrou uma dominação da loucura, ganhando o poder de enunciar sua verdade.

Numa perspectiva mais genealógica, em sua analítica do poder, Foucault (1977) demonstra que com a passagem de um diagrama soberano do poder, típico do mundo tradicional, para um diagrama disciplinar e biopolítico, o saber ganhou uma condição de instrumento político da modernidade (Danziato, 2012), de maneira que os poderes modernos - especialmente a disciplina e a biopolítica - operam através da utilização de técnicas e saberes que atravessam o corpo do indivíduo moderno. Não há mais uma incidência direta do poder sobre o corpo do sujeito como se observava no suplício; a forma de punição típica da lógica soberana. Os poderes modernos são sutis, estratégicos e minuciosos, operando através da produção de saberes sobre os indivíduos e populações.

O caráter pastoral do poder moderno (Foucault, 1999b) impõe outra estratégia de controle e dominação, que não a submissão direta, mas a "modos de subjetivação" constituídos e sustentados pelos saberes. Individualidades e subjetividades são assim, produzidas. O saber, então, passa a ser o grande operador político da modernidade, situando-se a partir da 
ciência como o novo lugar onde se produz a verdade, a qual se epistemologiza, e os saberes e discursos ganham o poder de enunciação da verdade dos sujeitos.

Não custa ressaltar que essa dinâmica não diz respeito exatamente ao caráter científico dos saberes - mesmo que esse aspecto discursivo também conte -, mas à sua posição na economia política do discursos (Foucault, 1999a). Por mais que a ciência tenha angariado um poder substancial de enunciação das verdades no mundo moderno, ainda assim, essa economia política é muito mais discursiva do que científico-metodológica. Trata-se de uma relação de "poder-saber" (Foucault, 2003) e não propriamente dos efeitos de verdade de uma descoberta científica.

Por outro lado, a inserção do discurso médico no laço social, através dos processos biopolíticos de higienização dos corpos, da espécie, das subjetividades e dos espaços urbanos, como uma forma estratégica de controle, alçou este discurso a uma posição de dominância nas políticas públicas não só de saúde, mas de controle social de uma forma geral (Foucault, 1979). O exercício do poder se "positiva" pela produção de saberes e modos de subjetivação.

Podemos agora entender que a dominância discursiva que permite a localização dos saberes e práticas psiquiátricas, assim como seus manuais de classificação - o $D S M-5$ e o CID-10 -, num lugar privilegiado na enunciação da verdade das subjetividades contemporâneas, advém de uma economia política dos discursos sustentada por uma estratégia biopolítica de controle dos corpos e das subjetividades, reduzindo a condição singular do sujeito a uma lógica biopolítica universalizante.

O mais grave dessa redução das singularidades e subjetividades à uma dimensão orgânica e cerebral é o caráter despolitizante dessas práticas e discursos, que fazendo assim, conseguem a proeza de domesticar os corpos e subjetividades, retirando-lhes a potência do singular e da crítica das estruturas, sejam elas a do sujeito, sejam do laço social. O que impera nos dias atuais é uma "ideologia apoliticista" (Zizek, 2015) que produz uma despolitização das práticas, dos discursos e dos saberes. A interrogação política dos saberes, da ciência e dos discursos fica, assim, comprometida em nome da enunciação de uma verdade, na maioria das vezes pseudocientíficas. Não por acaso, o pragmatismo e o empirismo cientificista imperam como o fundamento metodológico dessas práticas.

Para Foucault, portanto, o saber, e não necessariamente a ciência, agencia a economia política dos discursos no mundo moderno-contemporâneo. Essa conclusão nos remete a outra formulação, dessa vez proposta por Lacan (1969-70/1992) a partir da sua "topologia dos quatro discursos".

\section{Conclusão: Novos Discursos, Outras Subjetividades}

De forma muito semelhante à leitura de Foucault, Lacan também considera que o saber é o agente predominante do mundo moderno, sustentado por uma operação de atadura do saber e da verdade, estabelecida pela ciência e pela lógica universitária, determinando uma verdadeira "tirania do tudo-saber" (Lacan, 1968-69/2008).

O efeito dessa dominância do discurso universitário foi acreditar que através do saber poderíamos organizar, ou gerir, o real, intervindo de forma a suturar seus furos. Essa lógica discursiva produziu algumas experiências importantes no mundo moderno: o iluminismo e sua crença no caráter salvador da ciência; o comunismo e sua sustentação num saber revolucionário; o higienismo e sua suposição biopolítica de cura genética da espécie; ou mesmo o nazismo, com sua política de exceção e sua genética delirante, que realizaram a distopia da aplicação da lógica da produção à morte.

No mundo contemporâneo, portanto, existe uma "tirania do tudo-saber" (Lacan, 1968-69/2008). Há saber universitário para tudo, até para atividades as mais cotidianas, como arrumar uma mala, ou organizar seu guarda-roupa. O discurso da "gestão", característico do "novo espírito do capitalismo" (Boltanski \& Chiapello, 2009) fundamentado na lógica neoliberal, propõe-se para todas as áreas, inclusive no tratamento das subjetividades através de seu novo representante, o coaching.

De maneira que podemos entender essa dominância do discurso médico psiquiátrico no mundo atual como fundada, como dissemos, não em sua eficácia científica - mesmo que as medicações tenham uma eficácia -, mas sustentadas por essa cumplicidade entre a ciência e o capitalismo, na "gestão" biopolítica da vida, da espécie, ou mesmo dos corpos e das subjetividades.

Para Lacan (1969-70/1992), portanto, os modos de agenciamento dos discursos determinam a posição subjetiva, questão fundamental para compreender os efeitos da predominância das teorias biomédicas sobre as subjetividades contemporâneas. O discurso universitário, que tratamos acima, é agenciado pelo saber fechado, sem furos, o "tudo-saber". Nas práticas em que o saber se totaliza e assume um lugar de predominância discursiva, Lacan nos diz que o sujeito se encontra reduzido à condição de objeto da produção: "Vocês são os produtos da Universidade, e comprovam que a mais-valia são vocês" (p. 191). O sujeito se torna, aqui, o resto do processo mercadológico de produção do saber, que só será reintegrado ao campo discursivo sob a condição de movimentar ainda mais a produção ilimitada do saber. É o que se verifica com a proliferação das 'novidades psi', essas promessas de eliminação do sofrimento psíquico: a mais moderna droga farmacológica; a terapia da moda; o último livro de auto-ajuda, e assim por diante. No mercado do saber, o sujeito é continuamente convocado, chamado à cena, mas apenas para que se confirme o seu lugar objetificado, ou de 'mais- valia', como diria Lacan. 
Se o discurso universitário é regido pela lógica da totalização do saber, o discurso do mestre se mostra atravessado pelo movimento de "expropriação do saber", no qual o saber se desloca do sujeito em direção ao mestre. Enquanto agente de discurso, o mestre detém a verdade sobre o saber, verdade apropriada à custa do sujeito, que se deixa escravizar nas malhas da dialética discursiva. "O que designa a filosofia em toda a sua evolução? O roubo, o rapto, a subtração de seu saber à escravaria, pela operação do senhor" (Lacan, 1969-70/1992, p. 19). Mas não é apenas a evolução da filosofia que demonstra os laços discursivos agenciados pelo significante mestre. A história da constituição da medicina moderna, conforme vimos no tópico anterior, é marcada pela expropriação do saber do doente sobre sua própria doença, que se torna agora um saber (do) médico.

No discurso do mestre, verifica-se, portanto, a operação de poder sobre o saber do escravo, que Lacan escreveu sob a notação $\mathrm{S}_{1} \rightarrow \mathrm{S}_{2}$. O escravo e seu saber $\left(\mathrm{S}_{2}\right)$, ao trabalhar, contribuem para assegurar a posição do mestre $\left(\mathrm{S}_{1}\right)$, de uma forma análoga à maneira que a psicologia contribui para a hegemonia do saber psiquiátrico, aderindo cegamente aos manuais classificatórios. Assim, a relação entre mestre e escravo produz, por consequência, o rechaço do sujeito e seu fantasma (que se encontra abaixo do $S_{1}$, sob a barra), constituindo sua produção como um resto não integrável ao campo do discurso: o objeto $\alpha$ :

Mestre: $\quad \frac{\mathrm{S}_{1}}{\$} \frac{\mathrm{S}_{2}}{a}$

Lacan (1969-70/1992), em sua leitura do capitalismo e da modernidade, demonstrou que nessa passagem histórica, operou-se o que ela denomina por "mudança de mestre na modernidade", na qual se verifica uma igual mudança na posição do saber. Enquanto o mestre antigo $\left(\mathrm{S}_{1}\right)$ funcionava com agente no mundo tradicional, pré-moderno, o mestre moderno é fruto da conjunção da ciência e do capitalismo, e se caracteriza pela pretensão em totalizar o campo do saber $\left(\mathrm{S}_{2}\right)$, relativo ao discurso universitário. Assim, o capitalista e o universitário operaram em cumplicidade uma substituição do mestre antigo por um "mercado do saber" e um "mercado do gozo", próprio dos objetos, de maneira que o laço social moderno e contemporâneo é regido por uma alternância e cumplicidade entre o discurso universitário, cujo agente é o saber (S2) e o discurso do capitalista, que corrompe as regras da impossibilidade dos discursos.

$\begin{array}{ll}\text { Universitário: } & \frac{\mathrm{S}_{2}}{\mathrm{~S}_{1}} \frac{a}{\$} \\ \text { Capitalista: } & \frac{\$}{\mathrm{~S}_{1}} \frac{\mathrm{S}_{2}}{a}\end{array}$

No justo avesso do discurso do mestre, o discurso analítico devolve o saber a quem lhe é de direito: a regra da associação livre - "fale o que lhe vier à cabeça" - é uma aposta de que o sujeito sabe sobre o seu sofrimento, mesmo que julgue não o saber. Apenas um discurso agenciado por um lugar vazio, o lugar do objeto (lá onde se instaura a função analítica), abrirá espaço para a emergência do sujeito no laço social, sujeito intimamente implicado pelo desejo de saber.

Mas o que dizer da redução do sujeito à retórica biomédica que se verifica na atual psiquiatria descritiva? O que agencia esse tipo de discurso? Quais as relações entre saber e verdade em jogo na produção dos "si-mesmos neuroquímicos", para usar a expressão de Nikolas Rose (2013)?

A possibilidade de se dizer a partir da codificação neurobiológica introduz, de acordo com Rose (2013), uma espécie de ativismo político inteiramente original, fundado na concepção biológica da vida e dos sujeitos: as chamadas "biocidadanias". $\mathrm{O}$ estreitamento da distância entre organismo e funcionalidade, entre cérebro e psiquismo, constitui um saber amplamente disponível para quem desejar dele dispor. Os sites dos psicofármacos, as revistas de ampla circulação comercial, as reportagens televisivas, todos esses veículos propagam continuamente a descrição biológica dos afetos e das condutas. Nessa rede de propaganda, os bons entendedores se tornarão coparticipantes do diagnóstico, identificando, em si mesmos, o transtorno psiquiátrico. Tal identificação se mostra extremamente importante para uma luta política que se desenrola em duas frentes: 1. Na colaboração do paciente com o tratamento psiquiátrico; 2 . No avanço de novas pesquisas sobre os transtornos.

Sobre o primeiro ponto, Rose (2013) nos remete à lógica da gestão presente no tratamento psiquiátrico, em que o paciente é convidado a discutir ativamente com o seu médico o melhor plano terapêutico, que inclui estilos de vida e prescrição de psicofámacos. "A cidadania deve ser ativa. O paciente real ou potencial deve entender a sua depressão, trabalhar com médicos para obter o melhor programa de cuidados médicos, engajar-se em autotécnicas a fim de acelerar o processo de recuperação" (p. 204).

Mas, se a identidade neurobiológica possui um efeito individualizante, que convoca o paciente a responsabilizar-se pelo sucesso e pelo fracasso do tratamento, também tem um efeito coletivizador, que se relaciona à dimensão macropolítica das cidadanias biológicas. Multiplicam-se as pequenas coletividades, esses grupos de pessoas que partilham desequilíbrios neuroquímicos e genéticos em comum: associação de autistas, de bipolares, de depressivos, etc. Tais grupos pressionam a 
indústria psicofarmacológica, com seus respectivos cientistas, à produção de pesquisas que forneçam melhores explicações e modernos tratamentos aos seus transtornos, introduzindo o que Rose (2013) denominou de "tecnologias da esperança": um dia, os marcadores biológicos serão amplamente reconhecidos e a neurobiologia tratará dos mais diversos males da vida.

O saber totalizado, fruto do agenciamento do discurso universitário, ressurge, assim, pulverizado em uma multiplicidade de micro saberes, explicações moleculares, bioquímicas, para as variações do mal-estar. De outro modo, a expropriação do saber, agenciada pelo mestre, progressivamente, cede lugar à co-participação do saber, em que cada um se torna responsável por gerenciar seus planos de cuidado, esses últimos altamente individualizados. Tudo seguindo a lógica própria do neoliberalismo triunfante de nossos dias (Dardot \& Laval, 2016).

Essas novas formas de agenciamento nos encaminham ao radicalismo da foraclusão do sujeito no discurso biomédico, que se acha, então, aplainado nas codificações e decodificações da genética e dos neurotransmissores. E como produzir resistência quando a própria categoria de sujeito se encontra ameaçada? Como sugere Melman (2003), a psicanálise parece ser, hoje, o "último reduto do sujeito". Não por acaso, sofre todos os tipos de ataques e resistências por não se adequar aos parâmetros pragmatistas que a "biopolítica apoliticista" (Zizek, 2015) exige. Por isso mesmo, ela ganha uma crucial importância como prática clínica e discurso, de forma a manter, nos vários espaços produtores de saber, tais como as universidades e outras instituições regidas pela lógica médico-universitárias, um lugar para o sujeito e seu não-saber.

É preciso que uma denúncia do lugar predominante do saber no campo político na contemporaneidade seja feito. Isto Foucault já nos legou. Por outro lado, é preciso ilustrar uma prática cuja lógica não acompanha a premissa universitária da "tirania do tudo-saber" nem os efeitos perversos da pulverização neoliberal em micro saberes, mas, pelo contrário, que considere que um "não-saber" aí se mantém como causa do sujeito. Este é o nome do singular para a práxis psicanalítica.

\section{Referências}

American Psychiatric Association (2004). DSM-4: Diagnostic and Statistical Manual of Mental Disorder. São Paulo: Manole.

American Psychiatric Association. (2014). DSM-5: Manual diagnóstico e estatístico de transtornos mentais. Artmed Editora.

Boltanski, L., \& Chiapello, E. (2009). O novo espirito do capitalismo. São Paulo: WMF Martins Fontes.

Canguilhem, G. (1990). O normal e o patológico. Rio de Janeiro: Forense Universitária.

Calazans, R., \& Lustoza, R. Z. (2008). A medicalização do psíquico: Os conceitos de vida e saúde. Arquivos Brasileiros de Psicologia, 60(1), 124-131.

Clavreul, J. (1983). A ordem médica: Poder e impotência do discurso médico. São Paulo: Brasiliense.

Danziato, L. J. (2012). O Saber e a Verdade na Psicanálise e na Universidade. Psicol. Ciênc. Prof., 32(4), 872-881.

Dardot, P., \& Laval, C. (2016). A nova razão do mundo: Ensaio sobre a sociedade neoliberal. São Paulo: Boitempo.

Figueiredo, L. C. (2008). Revisitando as Psicologias: Da epistemologia à ética das práticas e discursos psicológicos. Petrópolis: Ed Vozes.

Figueiredo, L. C. (2012). Matrizes do pensamento psicológico. Petrópolis: Vozes.

Freire, J. (1994). A ética e o espelho da cultura. Rio de Janeiro: Rocco.

Foucault, M. (1977). Vigiar e Punir. Petrópolis: Vozes.

Foucault, M. (1979). O nascimento a medicina social. In. Machado, R. (org). Microfísica do Poder. Rio de Janeiro, Ed Graal, pp. 79-98.

Foucault, M. (1987). O nascimento da clínica. Rio de Janeiro: Forense Universitária. 
Foucault, M. (1991). A História da Loucura na Idade Clássica. São Paulo: Perspectiva.

Foucault, M. (1999a). A Ordem do Discurso. São Paulo: Loyola..

Foucault, M. (1999b). A Verdade e as Formas Jurídicas. Rio de Janeiro: Nau Ed.

Foucault, M. (2003). Estratégia Poder-Saber. Rio de Janeiro: Forense Universitária.

Genes, M. (2002). TDAH/I: Implicações no desenvolvimento infantil. In. Ferreira, C.A.M., Thompson, R. e Mousinho, R. (Org). Psicomotricidade Clínica. São Paulo: Ed. Lavise, pp. 91-107.

Gutfreind, C. (2016). Crônica dos afetos. Porto Alegre: Artmed.

Henriques, R. D. S. P. (2003). A remedicalização da Psiquiatria: Uma reflexão crítica sobre a revolução nosológica do DSM-III, (Doctoral dissertation). Universidade do Estado do Rio de Janeiro.

Infante, D. P. (2011). Psiquiatria para que e para quem. In. O livro negro da psicopatologia contemporânea. São Paulo: Letterman Editora, pp. 64-72.

Lacan, J. (1992). O Seminário, livro 17: O Avesso da Psicanálise. Rio de Janeiro: Jorge Zahar. (Originalmente publicado em 1969-70)

Lacan, J. (2008). O Seminário, livro 16: De um Outro ao outro. Seminário dos anos de 1968-69. Rio de Janeiro: Jorge Zahar. (Originalmente publicado em 1968-69)

Melman, C. (2003). O Homem sem gravidade: Gozar a qualquer preço. Rio de Janeiro: Companhia de Freud.

Miller, J. A. (2010). El Otro que no existe y sus comités de ética. Buenos Aires: Paidós.

Organização Mundial da Saúde. (1994). CID-10: Classificação Estatística Internacional de Doenças.(Vol. 1). São Paulo, Edusp.

Rose, N. (2013). A Política da Própria Vida: Biomedicina, poder e subjetividade no século XXI. São Paulo: Paulus.

Souza, L. (2013). Entre identificação e nomeação: Efeitos subjetivos da classificação psiquiátrica. (Dissertação de Mestrado), Programa de Pós-Graudação em Psicologia da Universidade de Fortaleza.

Thompson, R. (2002). A ação terapêutica da psicomotricidade na criança com TDAH. In Ferreira, C.A.M.; Thompson, R.; Mousinho, R. (Org) Psicomotricidade Clínica. São Paulo: Ed. Lavise, pp. 69-90.

Zizek, S. (2015). Problemas no paraíso: Do fim da história ao fim do capitalismo. Rio de Janeiro: Zahar.

Zarzanelli, R., Delgalarrondo, P., \&Benzato, C. E. M. (2014). O projeto research domain criteria e o abandono da tradição psicopatológica. Revista Latinoamericana de Psicopatologia Fundamental, 17(2), 328-341. Link 


\section{Endereço para correspondência}

Leonardo Danziato

Email: leonardodanziato@unifor.br

Ana Carolina B. L. Martins

Email: carolinablmartins@gmail.com

Sabrina Serra Matos

Email: sabrinamatos@unifor.br 